\title{
Survey-Based Research of Knowledge and Perception of Endodontic Treatment on an Indian Subpopulation
}

\author{
Shalin Ann Saji ${ }^{1}$ Chitharanjan Shetty ${ }^{1}$ Aditya Shetty ${ }^{1}$ Mithra N. Hegde ${ }^{1}$ \\ ${ }^{1}$ Department of Conservative Dentistry and Endodontics, AB Shetty \\ Memorial Institute of Dental Sciences, Mangalore, Karnataka, India \\ Address for correspondence Shalin Ann Saji, Department of \\ Conservative Dentistry and Endodontics, AB Shetty Memorial \\ Institute of Dental Sciences, Mangalore 575018, Karnataka, India \\ J Health Allied Sci ${ }^{\mathrm{NU}}$ 2022;12:162-167. \\ (e-mail: shalinannsaji91@gmail.com).
}

\begin{abstract}
Keywords

- Fear

- Pain

- Questionnaire

- Root canal treatment

Objective To assess the patients' knowledge and perceptions regarding endodontic treatment.

Materials and Methods A questionnaire-based survey was conducted in a group of 400 patients, consisting of questions based on sociodemographic details as well as their knowledge about endodontic treatment. The collected data was tabulated and analyzed using methods of descriptive analysis.

Results The majority of the respondents stated their level of knowledge regarding endodontic treatment as average.

Conclusion Within the limitations of the study, an improvement in the knowledge regarding endodontic treatment among patients was observed.

Clinical Significance Population-based surveys are useful for evaluating the community and patients' mentality toward endodontic treatment. Proper information regarding the treatment modalities can be explained to the patient based on their lack of information, which is of utmost importance to develop a positive approach to root canal treatment.
\end{abstract}

\section{Introduction}

Root canal treatment (RCT) is a procedure that involves the removal of damaged and diseased dental pulp and replacement by a sterile and inert substance. ${ }^{1}$ One of the most common endodontic procedures for which a patient visits the dentist is RCT. In routine dental practice, patients' awareness and knowledge regarding endodontic treatment play a significant role, as it influences the course and effects of treatment. ${ }^{2}$ Patients tend to delay or avoid dental treatments due to the fear of previously experienced pain. Apart from this, other reasons affect the choice of treatment plans like the patient's socioeconomic status, attitude, and prefer- ences. These patients are more prone to dental decay, have more missing teeth, and have less functioning teeth, according to studies, owing to inadequate oral health maintenance. ${ }^{3}$ A survey conducted by Janczarek et al found that patients' knowledge and awareness of endodontic treatment has improved and that the majority of patients surveyed are aware of the options available to them during endodontic treatment, including different types of anesthesia, RCT, modern techniques, and treatment outcome prediction. ${ }^{4}$

Another survey conducted by Sisodia et al reported a moderate level of awareness of endodontic treatment among the selected population. It also emphasized the significance of providing patients more information about the benefits of
DOI https://doi.org/ $10.1055 / \mathrm{s}-0041-1736451$ ISSN 2582-4287.

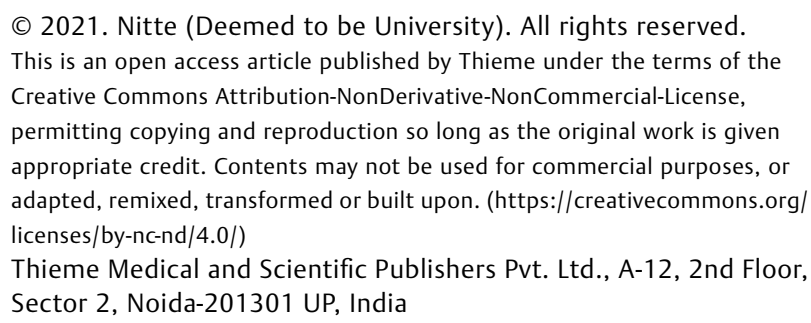


retaining teeth through endodontic therapy. ${ }^{1}$ Dental apprehension and expectation of pain had an imperative role on the patient's ability to comprehend the information given. ${ }^{2}$ Recognizing the reasons that result in distress among patients, consequently hindering them from undertaking RCT, is necessary. The population-based survey is a key step to adequately address the issue. ${ }^{5}$ This survey was conducted to evaluate the patients' knowledge and perceptions regarding endodontic treatment in an Indian subpopulation.

\section{Materials and Methods}

Institutional ethical clearance was obtained (ABSM/EC 22/2019 dated 28/06/2019). All the participants signed an informed consent declaration.

A self-administered questionnaire was prepared and distributed among 400 patients who had visited the department of conservative dentistry and endodontics. The inclusion criteria for the study were patients belonging to the age group of 18 to 65 years, who agreed to participate in the study. People associated with the field of dentistry were excluded. A pilot study was conducted to validate the questionnaire. A multiple-choice questionnaire consisting of sociodemographic details as well as their knowledge and perceptions about endodontic treatment was distributed (-Table 1). The questionnaire was prepared in Kannada, Malayalam, and English. Most of the respondents belonged to the south Canara district of Karnataka and the northern districts of Kerala.

\section{Statistical Analysis}

Data analysis was performed using methods of descriptive statistics like frequency and percentages.

\section{Results}

This is a simple observational study. The findings were tabulated, and the results were analyzed to find out patients' awareness about RCT. Results obtained are summarized in -Tables 2 and 3.

\section{Discussion}

The study group comprised 400 subjects in the age group of 18 to 65 years. Out of those, 224 (56\%) participants were females and 176 (44\%) were males. Out of the total participants, $30 \%$ were from urban areas, $46 \%$ from semiurban, and $24 \%$ from rural areas. As much as $12 \%$ of them had primary education, $52 \%$ with secondary education, and $36 \%$ with higher education. People who were employed accounted for $50 \%$ of the participants, $34 \%$ were students, and $16 \%$ were unemployed (-Table $\mathbf{2}$ ).

Responses to questions regarding knowledge and perceptions about endodontic treatment are summarized in -Table 3. While considering the experiences of patients regarding endodontic treatment, $68 \%$ of the participants had a history of RCT. Out of the total participants, 52\% had given the response that RCT is not painful. Majority of the patients (56\%) report to the dentist instead of trying home remedies in case of toothache. Out of those who have tried home remedies, 62\% report that home remedies did not help in relieving toothache.

The major concern associated with RCT accounted for pain (42\%), followed by the need for extraction despite undertaken treatment (26\%). As much as $20 \%$ of the participants were concerned about the need for multiple X-rays and 10\% about long treatment time. When participants were asked to identify the symptoms that require RCT, majority of the responses were strong spontaneous toothache (62\%), followed by pain during biting (16\%). As much as $10 \%$ of the participants drew attention to pain during chewing and $8 \%$ reported discolored tooth. The majority of the respondents define their level of knowledge about RCT as average and ask for details. (32\%). When asked if RCT is indicated for any toothache, only $36 \%$ agreed, while the remaining did not agree. A total of $88 \%$ of the participants agreed that medicines alone cannot resolve endodontic infections without the need for RCT.

The participants were asked about the factor that determines them to choose the place for RCT. The majority of the responses were professional staff ( $54 \%$ ), followed by painless treatment (20\%). Both free of cost treatment and easy access to the place accounted for $10 \%$ of the responses, followed by $6 \%$ of the respondents favoring friendly service ( - Table 3 ).

Endodontics has been one of the fastest-growing branches of dentistry. The predictable outcome of the treatment has been significantly influenced by the use of advanced methods. ${ }^{4}$ RCT is performed primarily for irreversible diseases of the pulp, which is the most common reason for seeking dental treatment. ${ }^{2}$ A study conducted by Klages et al demonstrates that patients visiting the dental office expect pain usually rather than experiencing during treatment. $^{6}$

People who are related to the field of dentistry have been excluded to make sure that the responses were either based on their previous experiences or expectations based on what the public hears about RCT. While analyzing the results of this survey, the majority of the respondents had undergone RCT. Most of them are aware that RCT is not painful. Patients can benefit from the use of local anesthesia and nitrous oxide, based on various recent reports, enhancing its effect. Preoperative intravenous (IV) sedatives and analgesics can be used as another form of premedication. General anesthesia is the alternative in extreme cases. ${ }^{7}$

A study conducted by Armfield et al reveals that patients avoid visits to the dentist, due to fear. ${ }^{8}$ Most of the surveyed patients admit that they immediately report to the dentist in case of spontaneous ailments in the mouth, and others tried home remedies. Respondents who had tried home remedies mostly opt for self-prescribed medicines. Natural home remedies like the use of warm saline rinses, clove oil dressings, and the use of cold compresses were also followed by some patients. In this survey, most of the patients' concerns regarding RCT were pain followed by the need for extraction despite treatment undertaken. Patients were also concerned 
164 Research of Knowledge and Perception of Endodontic Treatment Saji et al.

Table 1 Detailed questionnaire

\begin{tabular}{|c|c|c|c|}
\hline Sl. no. & Questions & \multicolumn{2}{|l|}{ Options } \\
\hline \multirow[t]{3}{*}{1.} & \multirow[t]{3}{*}{ Age } & a) $18-24$ years & b) 25-34 years \\
\hline & & c) 35-44 years & d) $45-54$ years \\
\hline & & e) $55-65$ years & \\
\hline 2. & Gender & a) Male & b) Female \\
\hline \multirow[t]{2}{*}{3.} & \multirow[t]{2}{*}{ Location } & a) Urban & b) Semi-urban \\
\hline & & c) Rural & \\
\hline 4. & Qualification & \multicolumn{2}{|c|}{$\begin{array}{l}\text { a) Primary education } \\
\text { b) Secondary education } \\
\text { c) Higher education }\end{array}$} \\
\hline \multirow[t]{2}{*}{5.} & \multirow[t]{2}{*}{ Occupation } & a) Employed & b) Unemployed \\
\hline & & c) Student & \\
\hline 6. & Have you ever undergone RCT? & a) Yes & b) $\mathrm{No}$ \\
\hline 7. & $\begin{array}{l}\text { Do you think root canal treatment is } \\
\text { painful? }\end{array}$ & a) Yes & b) No \\
\hline 8. & $\begin{array}{l}\text { Have you ever tried any home remedies to } \\
\text { relieve toothache? }\end{array}$ & a) Yes & b) No \\
\hline 9. & What home remedies have you tried? & \multicolumn{2}{|c|}{$\begin{array}{l}\text { a) Warm saltwater rinses } \\
\text { b) Use of cold compresses } \\
\text { c) Dressings with clove oil } \\
\text { d) Self-prescribed medicines } \\
\text { e) Others }\end{array}$} \\
\hline 10. & $\begin{array}{l}\text { Have you got any relief after trying home } \\
\text { remedies? }\end{array}$ & a) Yes & b) No \\
\hline 11. & $\begin{array}{l}\text { What concerns do you have regarding } \\
\text { RCT? }\end{array}$ & \multicolumn{2}{|c|}{$\begin{array}{l}\text { a) Pain } \\
\text { b) Need for multiple X-rays } \\
\text { c) Need for extraction despite undertaken treatment } \\
\text { d) Long treatment time } \\
\text { e) Others }\end{array}$} \\
\hline 12. & $\begin{array}{l}\text { What symptoms indicate the need to } \\
\text { undergo RCT? }\end{array}$ & \multicolumn{2}{|c|}{$\begin{array}{l}\text { a) Pain during chewing b) Pain during biting } \\
\text { c) Strong spontaneous toothache } \\
\text { d) Discolored tooth } \\
\text { e) Others }\end{array}$} \\
\hline 13. & Do you know anything about RCT? & \multicolumn{2}{|c|}{$\begin{array}{l}\text { a) I know a lot } \\
\text { b) Average knowledge, I ask for details } \\
\text { c) Average knowledge, am not interested in the course } \\
\text { d) I do not know anything } \\
\text { e) Knowledge from media }\end{array}$} \\
\hline 14. & $\begin{array}{l}\text { Does any toothache indicate RCT to be } \\
\text { done? }\end{array}$ & a) Yes & b) $\mathrm{No}$ \\
\hline 15. & $\begin{array}{l}\text { Can medicines alone resolve root canal } \\
\text { infections without the need for RCT? }\end{array}$ & a) Yes & b) $\mathrm{No}$ \\
\hline 16. & $\begin{array}{l}\text { What factor determines you to choose the } \\
\text { place for RCT? }\end{array}$ & \multicolumn{2}{|c|}{$\begin{array}{l}\text { a) Free of cost treatment b) Easy access to the place } \\
\text { c) Professional staff d) Friendly service } \\
\text { e) Painless treatment }\end{array}$} \\
\hline
\end{tabular}

Abbreviation: $\mathrm{RCT}$, root canal treatment.

about the need for multiple X-rays and a long treatment time.

The majority of the respondents agreed that strong spontaneous toothache indicates the need for RCT. In the present study, only $18 \%$ of the respondents did not know RCT, whereas a study conducted by Habib et al stated that $25.3 \%$ of the respondents did not know RCT. ${ }^{9}$ Patients are also aware that RCT is not indicated for all cases of toothache. While considering the patients' awareness about the adequacy of medicines in treating endodontic infections, the majority of them agreed that they are not enough in treating endodontic infections. This indicates that the majority of the studied sample recognize the importance of endodontic treatment, as antibiotics should be prescribed only in 
Table 2 Responses for sociodemographic details

\begin{tabular}{|c|c|c|c|}
\hline Question & Response & Frequency & Percent \\
\hline \multirow[t]{5}{*}{ Age } & a) $18-24$ years & 120 & 30.0 \\
\hline & b) 25-34 years & 144 & 36.0 \\
\hline & c) $35-44$ years & 56 & 14.0 \\
\hline & d) 45-54 years & 40 & 10.0 \\
\hline & e) 55-65 years & 40 & 10.0 \\
\hline \multirow[t]{2}{*}{ Gender } & a) Male & 176 & 44.0 \\
\hline & b) Female & 224 & 56.0 \\
\hline \multirow[t]{3}{*}{ Location } & a) Urban & 120 & 30.0 \\
\hline & b) Semiurban & 184 & 46.0 \\
\hline & c) Rural & 96 & 24.0 \\
\hline \multirow[t]{3}{*}{ Qualification } & a) Primary education & 48 & 12.0 \\
\hline & b) Secondary education & 208 & 52.0 \\
\hline & c) Higher education & 144 & 36.0 \\
\hline \multirow[t]{3}{*}{ Occupation } & a) Employed & 200 & 50.0 \\
\hline & b) Unemployed & 64 & 16.0 \\
\hline & c) Student & 136 & 34.0 \\
\hline
\end{tabular}

Table 3 Responses to questions regarding knowledge and perceptions about endodontic treatment

\begin{tabular}{|c|c|c|c|}
\hline Question & Response & Frequency & Percent \\
\hline \multirow{2}{*}{$\begin{array}{l}\text { Have you ever undergone } \\
\text { RCT? }\end{array}$} & a) Yes & 272 & 68.0 \\
\hline & b) No & 128 & 32.0 \\
\hline \multirow[t]{2}{*}{ Do you think RCT is painful? } & a) Yes & 192 & 48.0 \\
\hline & b) $\mathrm{No}$ & 208 & 52.0 \\
\hline \multirow{2}{*}{$\begin{array}{l}\text { Have you ever tried any home } \\
\text { remedies to relieve } \\
\text { toothache? }\end{array}$} & a) Yes & 176 & 44.0 \\
\hline & b) $\mathrm{No}$ & 224 & 56.0 \\
\hline \multirow{5}{*}{$\begin{array}{l}\text { What home remedies have } \\
\text { you tried? }\end{array}$} & a) Warm saltwater rinses & 120 & 30.0 \\
\hline & b) Use of cold compresses & 40 & 10.0 \\
\hline & c) Dressings with clove oil & 56 & 14.0 \\
\hline & d) Self-prescribed medicines & 160 & 40.0 \\
\hline & e) Others & 24 & 6.0 \\
\hline \multirow{2}{*}{$\begin{array}{l}\text { Have you got any relief after } \\
\text { trying home remedies? }\end{array}$} & a) Yes & 152 & 38.0 \\
\hline & b) $\mathrm{No}$ & 248 & 62.0 \\
\hline \multirow{5}{*}{$\begin{array}{l}\text { What concerns do you have } \\
\text { regarding RCT? }\end{array}$} & a) Pain & 168 & 42.0 \\
\hline & b) Need for multiple X-rays & 80 & 20.0 \\
\hline & c) Need for extraction despite undertaken treatment & 104 & 26.0 \\
\hline & d) Long treatment time & 40 & 10.0 \\
\hline & e) Others & 8 & 2.0 \\
\hline \multirow{5}{*}{$\begin{array}{l}\text { What symptoms indicate the } \\
\text { need to undergo RCT? }\end{array}$} & a) Pain during chewing & 40 & 10.0 \\
\hline & b) Pain during biting & 64 & 16.0 \\
\hline & c) Strong spontaneous toothache & 248 & 62.0 \\
\hline & d) Discolored tooth & 32 & 8.0 \\
\hline & e) Others & 16 & 4.0 \\
\hline
\end{tabular}


Table 3 (Continued)

\begin{tabular}{|c|c|c|c|}
\hline Question & Response & Frequency & Percent \\
\hline \multirow{5}{*}{$\begin{array}{l}\text { Do you know anything about } \\
\text { RCT? }\end{array}$} & a) I know a lot & 96 & 24.0 \\
\hline & b) Average knowledge, I ask for details & 128 & 32.0 \\
\hline & c) Average knowledge, am not interested in the course & 56 & 14.0 \\
\hline & d) I do not know anything & 72 & 18.0 \\
\hline & e) Knowledge from media & 48 & 12.0 \\
\hline \multirow{2}{*}{$\begin{array}{l}\text { Does any toothache indicate } \\
\text { RCT to be done? }\end{array}$} & a) Yes & 144 & 36.0 \\
\hline & b) No & 256 & 64.0 \\
\hline \multirow{2}{*}{$\begin{array}{l}\text { Can medicines alone resolve } \\
\text { root canal infections without } \\
\text { the need for RCT? }\end{array}$} & a) Yes & 48 & 12.0 \\
\hline & b) No & 352 & 88.0 \\
\hline \multirow{5}{*}{$\begin{array}{l}\text { What factor determines you } \\
\text { to choose the place for RCT? }\end{array}$} & a) Free of cost treatment & 40 & 10.0 \\
\hline & b) Easy access to the place & 40 & 10.0 \\
\hline & c) Professional staff & 216 & 54.0 \\
\hline & d) Friendly service & 24 & 6.0 \\
\hline & e) Painless treatment & 80 & 20.0 \\
\hline
\end{tabular}

Abbreviation: RCT, root canal treatment.

specific cases with systemic infection and as prophylaxis for other medical conditions. ${ }^{10}$ The knowledge regarding endodontic treatment is not only due to school education but also due to previous visits to the dental clinic, communication with peers, and the influence of mass media-television, newspapers, and Internet. ${ }^{2,4}$ Majority of the surveyed patients choose the place for RCT based on the services provided by professional staff. Iqbal et al in their study concluded that patients choose the dental service provider based on professional experience, staff courtesy, and friendly environment. $^{11}$

Over the last years, the knowledge regarding endodontic treatment among patients has been significantly increased. Patients are not just aware of the immediate pain relief but also about the prospects offered by the modern clinics, carrying out of the treatment at the highest level and adequate postoperative care by ensuring long-term radiological surveillance, allowing observation of results attained, aiding immediate intervention if required and monitoring the treatment effects. ${ }^{12,13}$

\section{Conclusion}

Within the limitations of the study, an improvement in the knowledge regarding endodontic treatment among patients was observed. Knowledge and awareness of patients about endodontic treatment differ among races and populations. The majority of the surveyed patients are aware of the advanced techniques available for endodontic treatment.

\section{Clinical Significance}

Questionnaire-based surveys in the population help evaluate the community and assess the patient's mentality toward RCT. It is of utmost importance, especially in developing countries like India, where oral health has been neglected by the people, mainly due to inadequate dental health knowledge or myths about the treatment. Proper information regarding the treatment modalities can be explained to the patient based on their lack of information, which is of utmost importance to develop a positive approach to RCT. The importance of saving natural teeth should be emphasized and misperceptions about endodontic treatment should be dissipated. Improving awareness in patients regarding endodontic treatment will change the patients' attitude and make them accept the treatment.

Conflict of interest

None declared.

\section{References}

1 Sisodia N, Yadav S, Nangia T, et al. Dental patients' knowledge and attitude towards endodontics - A survey. Pharm J Sci Biomed 2015;5:80-83

2 Purra AR, Sajad M, Ahangar FA, et al. Patient's awareness and knowledge of the root canal treatment in Kashmiri Population: a survey- based original research. International Journal of Contemporary Medical Research. 2018;5(07):G12-G15

3 Aldawsari M, Alamri HM. Public knowledge and perception regarding endodontic treatment in a Saudi population. J Int Oral Health 2017;9:255-257

4 Janczarek M, Cieszko-Buk M, Bachanek T, et al. Survey-based research on patients' knowledge about endodontic treatment. Zdrow Publiczne 2014;124:134-137

5 Bansal R, Jain A. An insight into patient's perceptions regarding root canal treatment: A questionnaire-based survey. J Family Med Prim Care 2020;9(02):1020-1027

6 Klages U, Ulusoy O, Kianifard S, Wehrbein H. Dental trait anxiety and pain sensitivity as predictors of expected and experienced 
pain in stressful dental procedures. Eur J Oral Sci 2004;112(06): 477-483

7 Montagnese TA. Why intravenous moderate sedation should be taught in graduate endodontic programs. J Dent Educ 2012;76 (03):288-290

8 Armfield JM, Heaton LJ. Management of fear and anxiety in the dental clinic: a review. Aust Dent J 2013;58(04):390-407

9 Habib AA, Dormant MD, Al Saysd T, et al. Dental patient's knowledge and awareness about root canal treatment in Syrian population: Survey-based research. IJRSR 2017;8:20583-20586
10 Aminoshariae A, Kulild JC. Evidence-based recommendations for antibiotic usage to treat endodontic infections and pain: a systematic review of randomized controlled trials. J Am Dent Assoc 2016;147(03):186-191

11 Iqbal M, Jameel A, Girach MM, et al. Factors affecting patient's choice of dental services. PODJ 2014;34:691-695

12 Parirokh M, V Abbott P. Various strategies for pain-free root canal treatment. Iran Endod J 2014;9(01):1-14

13 Murray CA, Saunders WP. Root canal treatment and general health: a review of the literature. Int Endod J 2000;33(01):1-18 